\title{
Fatores facilitadores e dificultadores à construção do TCC
}

O presente estudo teve como objetivo geral investigar os elementos relacionados à elaboração do Trabalho de Conclusão em Cursos de Graduação do campus Floriano da Universidade Federal do Piauí. Como instrumento de coleta de dados foi aplicado um questionário via Google Forms junto aos discentes que concluíram do TCC dos Cursos de Bacharelado em Administração, Licenciatura em Ciências Biológicas, Licenciatura em Pedagogia e Bacharelado em Enfermagem no período letivo 2019.1. O propósito do estudo foi identificar que fatores facilitam ou dificultam o processo de construção do trabalho monográfico, etapa obrigatória em todos os cursos mencionados. Os entrevistados relataram que o que mais facilitou foram a empatia do professor, a disponibilidade do orientador, a liberdade para escolher o tema, o domínio do tema por parte do orientador e o apoio da família e amigos. Os fatores que mais dificultaram foram a mudança de orientador no percurso, o tema escolhido pelo orientador, o acervo da biblioteca, o tempo e o custo direto e indireto para a elaboração do TCC.

Palavras-chave: Monografia; Graduação; Dificultadores; Facilitadores.

\section{Facilitating and harding factors to the construction of the TCC}

The present study aimed to investigate the elements related to the elaboration of the Conclusion Work (TCC) in Undergraduate Courses of the Floriano campus of the Federal University of Piauí. As a data collection instrument, a questionnaire via Google Forms was applied to the students who graduated from the Bachelor of Business Administration, Bachelor in Biological Sciences, Pedagogy and Nursing Bachelor Degree Courses 2019.1. The purpose of the study was to identify which factors facilitate or hinder the process of construction of monographic work, a mandatory step in all mentioned courses. Respondents reported that what most facilitated were the teacher's empathy, the availability of the advisor, the freedom to choose the topic, the mastery of the topic by the advisor and the support of family and friends. The most difficult factors were the change of advisor along the way, the theme chosen by the advisor, the library collection, the time and the direct and indirect cost for the preparation of the TCC.

Keywords: Monograph; University Graduate; Difficulties; Facilitators.

\section{Topic: Recursos Humanos}

Reviewed anonymously in the process of blind peer.
Received: 08/06/2020

Approved: 30/07/2020
Jairo de Carvalho Guimarães

Universidade Federal do Piauí, Brasil

http://lattes.cnpq.br/4540152132630356

http://orcid.org/0000-0002-5901-5026

jairoguimaraes@ufpi.edu.br

Francisco Dyego da Silva Sobrinho (iD

Universidade Federal do Piauí, Brasil

http://lattes.cnpq.br/2169809646638815

http://orcid.org/0000-0002-8249-1450

didi da silva95@hotmail.com

\section{Referencing this:}

GUIMARÃES, J. C.; SILVA SOBRINHO, F. D.. Fatores facilitadores e dificultadores à construção do TCC. Revista Brasileira de Administração Científica, v.11, n.3, p.82-99, 2020. DOI: http://doi.org/10.6008/CBPC2179-684X.2020.003.0006 


\section{INTRODUÇÃO}

O processo de formação no âmbito do Ensino Superior pressupõe a realização de várias e sequenciais etapas com vistas a preparar de maneira mais efetiva o futuro Bacharel ou Licenciado visando às contingências do mercado de trabalho. No bojo destas etapas, muitos cursos superiores exigem o Trabalho de Conclusão de Curso - TCC como elemento complementar à formação discente. O TCC, conforme preconiza cada Projeto Pedagógico do Curso - PPC, pode ser atendido em formato de monografia, artigo científico, Plano de Negócio, documentário, projeto de intervenção, elaboração de produtos, etc.

Constata-se, regra geral, que há no ambiente acadêmico uma certa apreensão por parte de expressivo contingente de discentes quanto à elaboração do Trabalho de Conclusão de Curso, cujos motivos são diversos e dependem de inúmeros contextos. Todavia, como se trata de um componente curricular compulsório em alguns cursos, possuindo o mesmo teor de obrigatoriedade das demais disciplinas constantes da matriz curricular, emergem alguns questionamentos em torno de sua construção, a qual requer muito mais do que um simples 'decoreba' como, por exemplo, numa disciplina centrada em conjecturas teóricas.

O TCC impõe ao discente não apenas o conhecimento prévio da temática a ser desenvolvida no curso de sua elaboração, mas exige um manejo rigoroso em vários aspectos, como: a definição do tema, a formatação do trabalho, a modelagem metodológica, a análise sintética e analítica da pesquisa, o domínio do corpus conceitual, a compreensão geral do contexto dos fundamentos que norteiam o estudo, a elaboração de objetivos concisos, claros e precisos, a composição alinhada do problema, a preparação de fichamentos visando à criação de elos epistemológicos consistentes e válidos, o tempo disponível, a exequibilidade, dentre outros.

A compreensão atual é que a etapa de elaboração do TCC não constitui a mera consecução de um nível de conhecimento, nem a produção de um trabalho acadêmico de caráter obrigatório e/ou apenas uma alternativa de avaliação final de um Curso Superior, mas a convicção de que elementos cognitivos rigorosos foram incorporados pelos formandos no percurso de sua formação acadêmica. Estes elementos são relevantes para o enfrentamento dos obstáculos presentes na vida pessoal e profissional se caracterizando, portanto, num estágio para além do cumprimento de fase formativa impositiva. Como exemplos dos reflexos decorrentes da construção do TCC consideram-se, no processo que o precede, no transcurso de sua modelagem e na repercussão de sua apresentação, os seguintes pontos: Estímulo ao desenvolvimento da pesquisa; Discernimento sobre o sentido epistemológico presente no estudo; Emergência de afinidades com linhas temáticas contemporâneas; Produção de conexões e elos conceituais; Aprimoramento da escrita e da análise crítica; Análise pormenorizada de teorias desenvolvidas sobre o tema; Interesse pela publicação de produção científica; Estímulo à docência; Produção de cocriação e inovação no ambiente acadêmico; Instigação em busca de respostas a eventuais dúvidas sobre o tema; Desejo de repensar modelos aspirando à implementação de soluções para os problemas sociais vigentes; Interesse em mitigar desequilíbrios regionais por meio de intervenções que intensifiquem o espírito empreendedor; Busca de parcerias setoriais 
com vistas a equalizar descompassos ambientais

Conforme a Lei de Diretrizes e Bases da Educação - LDB no 9.394, de 20 de dezembro de 1996, a Educação Superior tem por finalidade, dentre outras, formar diplomados nas diferentes áreas de conhecimento, habilitados a atuarem profissionalmente e para a participação no desenvolvimento da sociedade brasileira, além de incentivar o trabalho de pesquisa e investigação científica, visando ao desenvolvimento da ciência e da tecnologia.

Nessa perspectiva, as universidades e faculdades brasileiras instituíram o Trabalho de Conclusão do Curso como um instrumento de validação da formação acadêmica, incentivando, por meio dele, a pesquisa científica, bem como o aprofundamento do estudo a áreas delimitadas do curso de formação tocando, direta ou indiretamente, a sociedade, buscando produzir resultados que sejam significativos, aplicados e transformadores.

Porém, durante a elaboração do TCC, os discentes se deparam com fatores que podem facilitar ou dificultar a boa condução do mesmo, sendo este o objeto deste estudo. Dentre os estudos em torno da tratativa em questão destacam-se as pesquisas de Carboni et al. (2004), Santos et al. (2017) e Silva et al. (2019). Carboni et al. (2004), buscaram caracterizar o perfil dos alunos do 8ㅇ semestre de Graduação em Enfermagem e identificar os fatores que facilitam e dificultam, para os estudantes, a elaboração do TCC, concluindo, através de entrevista com 76 alunos, que as maiores dificuldades foram: tempo, custos e procura de um orientador; o que mais facilitou foram a oportunidade de aprender a realizar pesquisa, o fato de possuir um orientador e o poder de escolha do tema.

Santos et al. (2017) identificaram os fatores benéficos ou limitadores na percepção dos estudantes de Ciências Contábeis em relação ao desenvolvimento da pesquisa científica por meio do TCC, observando que os estudantes de Contabilidade demonstraram vários aspectos favoráveis que motivam o desenvolvimento da pesquisa científica na sua formação acadêmica. Restou evidenciado o reconhecimento de que o acompanhamento do orientador é essencial para a execução e a qualidade da pesquisa. Mais recentemente, Silva et al. (2019) verificaram as dificuldades do processo de orientação do TCC, sob a percepção dos docentes de Ciências Contábeis de Instituições de Ensino Superior da grande Recife. Constatou-se que a maioria dos docentes apresentou muitas orientações durante os últimos dois semestres, tendo dificuldade na redação dos seus orientandos nos trabalhos, bem como na falta de assimilação e seguimento da metodologia, o cronograma, o conhecimento das normas e as formas como as referências devem ser citadas, a lógica que deve seguir, a maneira como os resultados devem ser apresentados e, por fim, a importância da correlação entre o tema, problema, objetivos, método e a conclusão.

Inobstante estes estudos, observa-se que são escassas as pesquisas que trazem à tona os fatores facilitadores ou dificultadores a elaboração do TCC na Graduação sob a perspectiva dos discentes numa análise comparativa entre vários cursos superiores, bem como não discriminam se esses fatores são de categoria social, psicológica, de produção técnica e econômica. Também não verificam quais desses fatores predominam dentre os investigados e como tais aspectos influenciam a nota e, com isso, o sucesso ou o fracasso do TCC. Com base na proposta e levando em consideração a possibilidade de que alguns dos fatores 
(dificultadores e/ou facilitadores) podem ser comuns aos formandos dos quatro cursos pesquisados, identificou-se a relevância em proceder a uma pesquisa que aponte que aspectos se posicionam no entorno da produção técnica do TCC, considerando que os discentes, não raro, apontam-no como a fase mais complexa na formação a que estão submetidos. Neste sentido, emerge o seguinte problema de pesquisa: Quais fatores facilitam ou dificultam a elaboração do Trabalho de Conclusão em um Curso de Graduação?. Em consonância com a problemática da pesquisa, o objetivo geral do estudo foi investigar os elementos determinantes da elaboração do Trabalho de Conclusão de Curso da Graduação, a partir de aplicação de questionário junto aos discentes que vivenciaram a elaboração do TCC dos Cursos Bacharelado em Administração, Licenciatura em Ciências Biológicas, Licenciatura em Pedagogia e Bacharelado em Enfermagem da Universidade Federal do Piauí (UFPI). Foram definidos os seguintes objetivos específicos: Identificar quais fatores influenciam a elaboração do TCC, elencando-os em fatores de categoria social, psicológica, de produção técnica e econômica, e verificar quais desses fatores predominam entre os entrevistados. Levando em consideração o fato de o TCC ser obrigatório e garantia de aquisição de diploma de Graduação por constituir, em tese, comprovação da aptidão do formando à atuação no mercado de trabalho, e baseado em estudos anteriormente realizados a respeito da problemática em questão, como o de Carboni et al. (2004) que comprovaram que existem aspectos que dificultam e facilitam a elaboração do TCC na área de Enfermagem, fez-se necessário a busca de dados mais atualizados e a ampliação do campo de formação sob investigação a fim de analisar a influência dos fatores que intervêm na elaboração do TCC na Graduação, avaliando se são fatores comuns aos quatro cursos ou se há revelações que permitam aferir a concentração de fatores em determinado curso.

\section{REVISÃO TEÓRICA}

A fase final de um curso de Graduação carrega, pelo natural desgaste durante o percurso formativo, um leque de sentimentos e apreensões. A certeza de que os percalços vivenciados serão superados, a convicção de que toda conquista impõe compromisso, dedicação e disciplina e a proximidade com a última volta do ponteiro são determinantes para premiar o sucesso de uma trajetória marcada por alguns reveses. A construção do TCC se constitui em uma etapa por vezes temida, por vezes experienciada como uma oportunidade de aprofundar dado tema, mirando em soluções práticas. Entender os fatores que orbitam a sua elaboração é o propósito do estudo, cujo corpo teórico será visto a seguir.

\section{O Trabalho de Conclusão de Curso - TCC}

Na concepção de Severino (2007), a expressão monografia indica uma forma específica de um trabalho científico. Julga-se monografia o trabalho que delimita sua abordagem a uma única temática e o problema com uma análise especificada. Severino (2007) ao falar sobre o TCC menciona que "para a grande maioria, ele representa a primeira experiência de realização de uma pesquisa. Como vivência de produção de conhecimento, contribui significativamente para uma boa aprendizagem". Cunha et al. (2015) e Silva et al. (2019), têm análise convertente ao considerar o Trabalho de Conclusão de Curso como um formato de 
pesquisa acadêmica realizada sobre temáticas específicas voltadas para áreas teórico-práticas e de formação profissional referente ao curso de formação, a ser utilizada como avaliação final de graduandos e pósgraduandos do ensino superior, podendo ser apresentado na forma de monografia, artigo, projeto, entre outros, com defesa pública diante de banca analisadora. Durante et al. (2019) afirmam que

A monografia não é o único formato de TCC. Outras modalidades são contempladas nas DCN e são consideradas por instituições e cursos obrigatórias para a conclusão deles, tais como: produção de artigos científicos, papers, relatórios de estágios e projetos de iniciação científica. Além disso, o termo monografia é empregado para manuscritos tanto na graduação quanto na pós-graduação, sendo dissertação (para mestrado) e a tese (para doutorado) tipos de monografia, diferenciando pela profundidade em que o assunto é abordado.

Skora et al. (2006) relatam que o TCC representa um instrumento para que o aluno demonstre os conhecimentos e habilidades adquiridos no decorrer do curso e, assim, receber seu diploma de graduação. Pelos relatos assentados, pode-se concluir que o Trabalho de Conclusão de Curso é ferramenta essencial e obrigatória não apenas para a obtenção do diploma de conclusão de curso superior, mas adicionalmente por se revelar como instrumento definidor da qualidade do aprendizado do concludente, mostrando se o mesmo se encontra apto a atuar profissional e socialmente na sua área de formação. Ademais, o produto do TCC pode desvelar conhecimentos sobre determinado fenômeno, permitindo a sua aplicação prática no universo social.

\section{Importância do Trabalho de Conclusão de Curso para a Academia}

Peixoto et al. (2014) relatam que o TCC possibilita a ampliação do aprendizado já adquirido pelo discente no decorrer do curso e pode ser considerado um procedimento de iniciação científica, enquadrando-se como uma ferramenta metodológica na busca de significados, fazendo alcançar novos conhecimentos. Desse modo, o TCC vai além de assegurar a aquisição do diploma, tomando caráter de incentivador da iniciação à pesquisa científica, podendo ocasionar o crescimento e desenvolvimento do estudo acerca do tema pesquisado chegando a descobertas importantes à ciência. Conforme Neves et al. (2007), o TCC pode ser considerado instrumento fundamental para solidificação das habilidades adquiridas durante o curso, sendo ele um recurso hábil visando a assegurar o desfecho de um percurso de formação, instigando o concludente a buscar o aprofundamento ou aprimoramento de um tema no âmbito do seu campo de atuação. Assim, o discente adquire diferentes competências e as consolida no TCC. Isso se dá pelo fato de que o estudo-base para a confeç̧ão da monografia gera uma aproximação com a realidade da profissão, através da solução de problemas do dia a dia da área pesquisada. Com efeito, Neves et al. (2007) assevera que

O TCC, [...] torna-se ferramenta fundamental para um profissional cuja atuação o coloca em contextos que the exigem flexibilidade, agilidade, criatividade para propor soluções, enfrentar adversidades, com um mercado regido pelas relações de competitividade e incerteza. Para alinhar-se a essa realidade é necessário articular ensino - tecnologia pesquisa, o que deve fundamentar a preparação desse perfil profissional.

Assim, pode-se considerar o Trabalho de Conclusão de Curso como uma experiência que mira no mercado de trabalho, potencializando as competências e as habilidades do aluno para atuação deste na 
profissão que escolheu. Corroborando com isso, os Projetos Pedagógicos dos Cursos (PPC's) de Graduação em Bacharelado em Administração, Licenciatura em Pedagogia, Licenciatura em Ciências Biológicas e Bacharelado em Enfermagem da UFPI - Campus Floriano, consideram o TCC como mecanismo de validação da formação acadêmica desenvolvida por meio de monografia a respeito de tema relevante da área estudada, mostrando a direta ligação entre o trabalho final do curso com áreas de atuação dos futuros profissionais. Conforme a Lei no 9.394, de 20 de dezembro de 1996, a qual estabelece as diretrizes e bases da educação nacional, em seu artigo 43, define que a Educação Superior, em linhas gerais, tem como objetivo estimular a criação e o desenvolvimento cultural, do espírito científico e do pensamento reflexivo, a fim de formar diplomados dos diversos campos do conhecimento, através do incentivo ao trabalho científico, capazes de atuar na sociedade com compreensão a respeito do mundo presente, incentivando o trabalho de pesquisa e investigação científica, visando o desenvolvimento da ciência e da tecnologia e da criação e difusão da cultura, desenvolvendo o entendimento do homem e do meio em que vive (BRASIL, 1996).

Para o cumprimento do estabelecido em Lei, e de acordo com Silva et al. (2019), para os alunos obterem grau nas universidades e faculdades, é obrigatório execução de trabalhos de pesquisa de conclusão de curso e/ou monografia. Para isso, o Trabalho de Conclusão do Curso (TCC) se dá como uma ferramenta de estímulo à pesquisa e ao ensino, constituindo um trabalho desenvolvido a respeito de um tema relacionado com a área de formação do graduando, tendo como objetivo garantir a conclusão do curso, sendo ele um trabalho de iniciação científica (MÜLLER et al., 2003). As Resoluções CES/CNE no 4, de 13 de julho de 2005 (BRASIL, 2005), CNE/CES no 7, de 11 de março de 2002 (BRASIL, 2002), CNE/CES no 3, de 7 de novembro de 2001 (BRASIL, 2001) e CNE/CP № 1, de 15 de maio de 2006 (BRASIL, 2006), que instituem as Diretrizes Curriculares Nacionais dos Cursos de Graduação de Bacharelado em Administração, Ciências Biológicas, Enfermagem e Licenciatura em Pedagogia, respectivamente, preveem que as Instituições de Ensino Superior expressem, através do seu Projeto Pedagógico (PPC), a organização do curso por completo, incluindo nele o Trabalho de Conclusão de Curso.

Analisando as Resoluções acima, constatou-se que os Projetos Pedagógicos dos Cursos estudados na presente pesquisa determinam que o TCC deverá ser desenvolvido na modalidade de monografia, contendo, obrigatoriamente, critérios, procedimentos e mecanismos de avaliação, além das diretrizes técnicas relacionadas com a sua elaboração, devendo ser apresentado à banca examinadora, pesquisa diretamente relacionada ao curso do concludente. Portanto, tem-se que o TCC não é somente considerado um elemento obrigatório no percurso formativo, mas, sobretudo, um produto que tem a intenção de evidenciar possíveis soluções para questões envolvendo o campo de atuação do concludente, sendo, destarte, relevante não apenas par a academia, mas para a sociedade em geral.

\section{Fatores Facilitadores e Dificultadores na Construção do TCC}

Em estudo desenvolvido por Carboni et al. (2004), que buscaram determinar o perfil dos graduandos do 8o período do Curso de Enfermagem de uma escola privada e identificar os fatores que facilitam e dificultam a elaboração do TCC, foi constatado que existem fatores que facilitam e dificultam a elaboração 
do Trabalho de Conclusão de Curso, verificando que os aspectos facilitadores que mais predominaram foram a oportunidade para aprender a realizar pesquisa, o fato de possuir um orientador e o poder de escolha do tema a ser convertido em produto científico (TCC). Já os aspectos dificultadores mais relatados foram tempo, custos e procura de um orientador, conforme pode ser verificado nos Quadros 1 e 2, os quais são dispostos em categorias.

Quadro 1: Fatores que facilitaram a elaboração do TCC.

\begin{tabular}{l}
\hline FATORES FACILITADORES \\
\hline Oportunidade para aprender a realizar pesquisa Científica \\
Possuir um orientador \\
Escolha do tema \\
Relação professor-aluno \\
Hábito de leitura \\
Motivação à pesquisa \\
Possibilidade de realizar o TCC em dupla \\
Não ter necessidade de apresentação oral \\
Cronograma a cumprir \\
Construção do conhecimento científico \\
Acesso ao material bibliográfico nas bases de dados \\
Apresentação em pôster
\end{tabular}

Fonte: Carboni et al. (2004).

Quadro 2: Fatores que dificultaram a elaboração do TCC.

\begin{tabular}{l}
\hline FATORES DIFICULTADORES \\
Tempo \\
Custo \\
Procura de um orientador \\
Exigência em realizar o TCC para aprovação no curso \\
Obrigatoriedade de seguir uma metodologia \\
Relação professor-aluno \\
Não possuir o hábito de leitura \\
Apresentação em pôster \\
Acesso ao material bibliográfico nas bases de dados \\
Desmotivação à pesquisa \\
Cronograma a cumprir \\
Possibilidade de realizar o TCC em dupla
\end{tabular}

Fonte: Carboni et al. (2004).

Em outro estudo no mesmo sentido, Santos et al. (2017) identificaram os fatores que podem ser considerados como benéficos ou limitadores na percepção dos estudantes de Ciências Contábeis em relação ao desenvolvimento da pesquisa científica por meio do Trabalho de Conclusão de Curso, observando que os estudantes descreveram tanto aspectos favoráveis quanto desfavoráveis relacionados à motivação para o desenvolvimento do TCC, sendo possível verificar que as principais dificuldades encontradas foram: a construção textual, a delimitação do tema para a pesquisa, a identificação de referências para serem utilizadas no estudo, a aplicação das normas ABNT e a realização das etapas científicas que são exigidas ao trabalho científico. Verifica-se, portanto, que o processo que envolve a elaboração do Trabalho de Conclusão de Curso, independentemente do curso de Graduação sob investigação, contém um rol de fatores psicológicos, materiais, sociológicos, cognitivos, relacionais -, os quais dão um panorama ampliado das vinculações - facilidades e dificuldades - que produzem as apreensões, expectativas, hesitações, perspectivas e sentimentos presentes no sistematizado modelo implementado por meio das estratégias e dos enredos negociados entre professor-orientador e concludente. 


\section{METODOLOGIA}

A presente pesquisa apresenta-se, quanto à sua abordagem, como um estudo quantitativo, que segundo Appolinário (2016) "[...] prevê a mensuração de variáveis predeterminadas, buscando verificar e explicar sua influência sobre outras variáveis". Em relação à sua natureza, trata-se de um estudo descritivoexploratório. É descritivo, segundo Appolinário (2016), por ser aquele feito apenas para descrever o que se é observado, sem que altere o resultado do fenômeno; também se designa como um estudo exploratório, o qual na concepção de Englert et al. (2018), a partir do enunciado de Malhorta (2006), significa o levantamento de informações sobre um determinado objeto, suas condições, complexidades e delimitações, buscando conhecer com mais profundidade o fenômeno em questão, tendo em vista a possibilidade de, pelo dinamismo e flexibilidade comuns a estudos desta natureza, promover novas ideias e percepções. A pesquisa tem a intenção, portanto, de explorar o fenômeno em sua perspectiva desveladora, buscando ampliar a compreensão acerca dos fatores que envolvem a construção do TCC, promovendo uma análise comparativa entre quatro cursos de Graduação. Para realização do estudo, foi utilizada a técnica de coleta de dados survey, considerando a mesma como um tipo de investigação quantitativa que coleta dados e informações a partir de características e opiniões de grupos de indivíduos, encontrando resultados que podem ser generalizados ao todo, desde que a amostra coletada seja representativa. Para o mesmo será utilizada a Escala de Intensidade Likert de 5 pontos, conforme pode ser verificado no Quadro 3.

Quadro 3: Escala de Intensidade Likert.

\begin{tabular}{|l|l|l|l|l|}
\hline Discordo totalmente & Discordo em parte & Indiferente & Concordo em parte & Concordo totalmente \\
\hline & & & & \\
\hline
\end{tabular}

Em observância às pesquisas anteriormente realizadas em torno da questão, objeto do presente estudo, e com o intuito de avaliar os fatores que facilitam ou dificultam a elaboração do Trabalho de Conclusão de Curso da graduação, foi aplicado um questionário aos egressos dos Cursos de Bacharelado em Administração e Enfermagem e de Licenciatura em Ciências Biológicas e Pedagogia da Universidade Federal do Piauí - Campus Amílcar Ferreira Sobral (Floriano/PI). Segundo a ideia de Cervo et al. (2007) “o questionário é a forma mais usada para coletar dados, pois possibilita medir com mais exatidão o que se deseja". Tendo em vista o caráter quantitativo do estudo, optou-se por aplicar o questionário por intermédio da ferramenta Google Forms, devido os respondentes já terem concluído o curso (período letivo 2019.1), não tendo como ser aplicado pessoalmente. Os pesquisados, foram, portanto, sujeitos já formados nos quatro cursos sob análise. O presente estudo foi aprovado pelo Comitê de Ética em Pesquisa da Universidade Federal do Piauí, por meio do CAAE (Certificado de Apresentação para Apreciação Ética) número 84729718.6.0000.5214.

\section{RESULTADOS E DISCUSSÃO}

A abordagem junto aos sujeitos da pesquisa foi feita no período de 20 de agosto a 04 de setembro de 2019, por meio do Google Forms, enviado ao endereço eletrônico individual, cuja listagem foi obtida junto às Coordenações dos Cursos de Administração, Ciências Biológicas, Enfermagem e Pedagogia. Do total de 87 
encaminhamentos feitos, houve retorno de 28 respostas, correspondendo a $32 \%$ do universo. Do total de 28 respondentes, $61 \%$ são do gênero feminino e 39\% do gênero masculino. A Tabela 1 representa a quantidade de questionários encaminhados e a efetividade percentual das respostas obtidas, por curso.

Tabela 1: Contingente de respondentes.

\begin{tabular}{l|l|l|l}
\hline Cursos & Questionários enviados & Questionários respondidos & \% respondidos \\
\hline Administração & 16 & 11 & $69 \%$ \\
\hline Ciências Biológicas & 14 & 6 & $43 \%$ \\
\hline Pedagogia & 50 & 10 & $20 \%$ \\
\hline Enfermagem & 7 & 1 & $14 \%$ \\
\hline Total dos sujeitos da pesquisa & $\mathbf{8 7}$ & $\mathbf{2 8}$ & $32 \%$ \\
\hline
\end{tabular}

Na Tabela 1, observa-se que o Curso de Administração teve o maior número de respondentes, sendo que dos 16 questionários enviados para o referido curso, 11 tiveram retorno, representando 69\% da pesquisa. Em segundo lugar está o Curso de Ciências biológicas, representando $43 \%$ da pesquisa. Os demais cursos tiveram uma resposta de menor intensidade, visto que, de acordo com os dados, no curso de Pedagogia, dos 50 questionários enviados, apenas 10 questionários foram respondidos, ou seja, apenas $20 \%$ dos questionários tiveram retorno. O Curso de Enfermagem foi o que teve a menor participação, sendo que apenas 1 (um) aluno do curso respondeu.

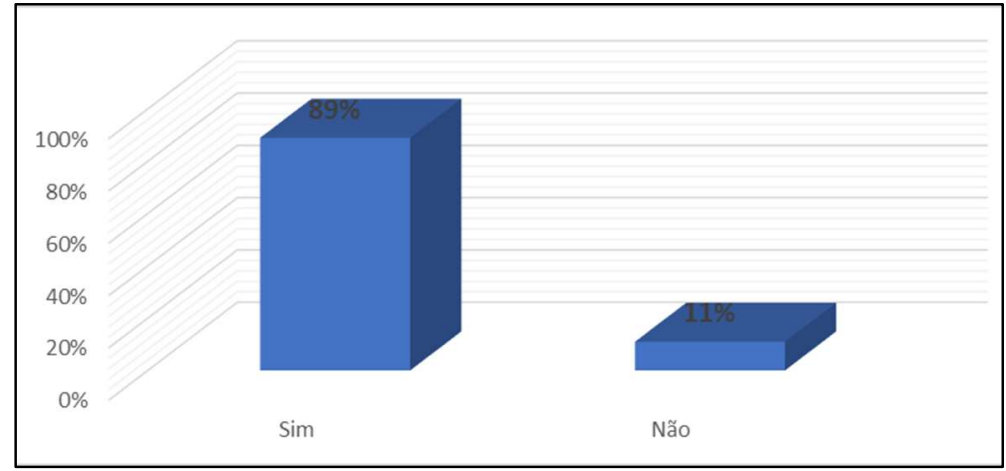

Gráfico 1: Primeiro Trabalho de Conclusão de Curso.

O Gráfico 1 mostra os resultados acerca da indagação feita aos alunos participantes do estudo, se estes já haviam, em algum momento, feito um outro TCC ou se era o primeiro TCC no percurso formativo. A proposta aqui foi conhecer se o egresso realizou mais de um TCC, o que poderia produzir outras implicações no tocante aos fatores relacionados à sua elaboração. De acordo com os dados obtidos no Gráfico 1, podese afirmar que a grande maioria, correspondendo a $89 \%$ dos pesquisados, fizeram apenas um Trabalho de Conclusão de Curso, o que leva a crer que, possivelmente, em razão de ser o primeiro contato com o TCC, os egressos tenham convivido com maiores dificuldades do TCC do que os $11 \%$ que haviam produzido um ou mais TCC. A ideia desta questão foi desvelar se, pelo fato de ter se envolvido com a elaboração do TCC em algum momento anterior, o egresso poderia confirmar que os obstáculos à sua elaboração foram superados ou suavizados, tendo em vista uma nova experiência com o processo de construção do componente curricular obrigatório para a sua formação.

Com o intuito de obter maior clareza e fidedignidade ao trabalho, foi perguntado aos participantes que responderam NÃO em relação à pergunta 3 [Este é o seu primeiro Trabalho de Conclusão de Curso?], 
quais os motivos que os impediram de realizar o TCC da primeira vez?. De acordo com os respondentes (Quadro 4), uma das dificuldades encontradas foi a falta de oportunidade e de tempo para se dedicar à construção do estudo; outra resposta obtida foi que não houve nenhum impedimento, realizando a pesquisa sem dificuldade alguma, mas que ao final a nota obtida foi insuficiente para a aprovação; por fim, a última resposta relatada foi a impossibilidade de conciliação do emprego com o estudo, asseverando que é difícil fazer essa combinação, tornando-se uma grande complexidade para a vida acadêmica.

Quadro 4: Dificuldades encontradas na elaboração do $1^{\circ}$ TCC.

\begin{tabular}{|l|l|}
\hline Dificuldades & QTD. \\
\hline Falta de oportunidade e de tempo & $33,33 \%$ \\
\hline Não houve impedimento & $33,33 \%$ \\
\hline Não conciliação com o emprego & $33,33 \%$ \\
\hline
\end{tabular}

Referente à pergunta 5 [No percurso de construção do seu TCC, que fatores indicados a seguir facilitaram o desenvolvimento do seu trabalho?], seguem as posições no Gráfico 2 e na Tabela 2, representando os resultados encontrados quanto aos fatores facilitadores na elaboração do TCC, segundo os pesquisados.

\section{Fatores Facilitadores}

O Gráfico 2 mostra o resultado geral dos 4 cursos estudados nesta pesquisa, mostrando que a empatia do professor, a disponibilidade do orientador, a liberdade para a escolha do tema, o domínio do tema pelo orientador e o apoio da família são os fatores que mais contribuíram para a finalização do TCC, conforme relataram os entrevistados. Estando em consonância parcial com o estudo de Carboni et al. (2004) que, resumidamente, afirmaram que os principais aspectos facilitadores são a oportunidade para aprender a realizar pesquisa, o fato de possuir um orientador e o poder de escolha do tema a ser convertido em produto científico (TCC), estes fatores prevaleceram no presente estudo, tendo se destacado dentre os demais. Resta induvidoso que a construção do TCC é uma troca mútua entre orientando e orientador.

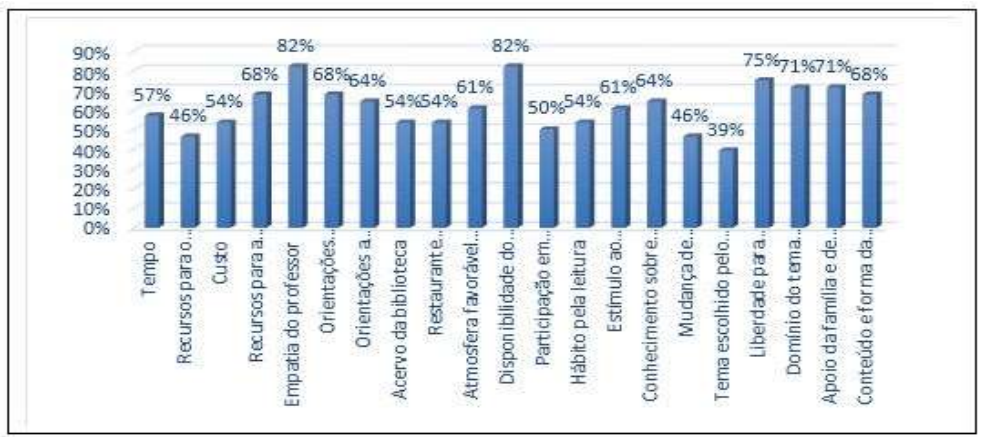

Gráfico 2: Fatores Facilitadores para a construção do TCC.

Analisando o Gráfico 2, é possível concluir que o orientador é fundamental para esse processo. Entende-se que um fator está ligado diretamente ao outro, pois, no processo de elaboração, além da empatia do professor, é aconselhável que o orientando escolha um tema na área em que ele tenha mais afinidade, escolhendo um orientador que tenha domínio no tema optado, além de ter disponibilidade para o acompanhar nessa elaboração. Restou evidenciado que fatores, sob o ponto de vista do discente, como 
empatia, domínio do tema e disponibilidade de tempo para orientar, são fundamentais para o sucesso e elaboração de um TCC.

Tabela 2: Fatores Facilitadores para a construção do TCC por curso.

\begin{tabular}{|c|c|c|c|c|c|}
\hline \multicolumn{2}{|l|}{ Facilitadores } & \multicolumn{4}{|l|}{ Cursos } \\
\hline Aspecto & $\%$ & Administração & Pedagogia & Ciências Biológicas & Enfermagem \\
\hline Empatia do professor & $82 \%$ & $39 \%$ & $35 \%$ & $26 \%$ & $0 \%$ \\
\hline Disponibilidade do orientador & $82 \%$ & $43 \%$ & $30 \%$ & $26 \%$ & $0 \%$ \\
\hline Liberdade para escolher o tema & $75 \%$ & $43 \%$ & $33 \%$ & $24 \%$ & $0 \%$ \\
\hline Domínio do tema pelo orientador & $71 \%$ & $40 \%$ & $30 \%$ & $30 \%$ & $0 \%$ \\
\hline Apoio da família e de amigos & $71 \%$ & $35 \%$ & $30 \%$ & $30 \%$ & $5 \%$ \\
\hline Recursos para a realização da pesquisa de campo & $68 \%$ & $32 \%$ & $37 \%$ & $32 \%$ & $0 \%$ \\
\hline Orientações presenciais sistemáticas & $68 \%$ & $47 \%$ & $21 \%$ & $32 \%$ & $0 \%$ \\
\hline Orientações a distância sistemáticas & $64 \%$ & $33 \%$ & $33 \%$ & $33 \%$ & $0 \%$ \\
\hline Conhecimento sobre as Normas da ABNT & $64 \%$ & $33 \%$ & $28 \%$ & $33 \%$ & $6 \%$ \\
\hline Atmosfera favorável à docência & $61 \%$ & $35 \%$ & $35 \%$ & $29 \%$ & $0 \%$ \\
\hline Estímulo ao desenvolvimento da pesquisa & $61 \%$ & $24 \%$ & $41 \%$ & $35 \%$ & $0 \%$ \\
\hline Tempo & $57 \%$ & $25 \%$ & $44 \%$ & $31 \%$ & $0 \%$ \\
\hline Custo direto e indireto para a elaboração do TCC & $54 \%$ & $33 \%$ & $33 \%$ & $33 \%$ & $0 \%$ \\
\hline Acervo da biblioteca & $54 \%$ & $40 \%$ & $20 \%$ & $33 \%$ & $7 \%$ \\
\hline Restaurante Universitário funcionando no jantar & $54 \%$ & $40 \%$ & $33 \%$ & $27 \%$ & $0 \%$ \\
\hline Hábito pela leitura & $54 \%$ & $27 \%$ & $33 \%$ & $33 \%$ & $7 \%$ \\
\hline Participação em projetos de Iniciação Científica & $50 \%$ & $14 \%$ & $50 \%$ & $36 \%$ & $0 \%$ \\
\hline Recursos para o deslocamento até o campus & $46 \%$ & $31 \%$ & $31 \%$ & $38 \%$ & $0 \%$ \\
\hline Mudança de orientador & $46 \%$ & $46 \%$ & $38 \%$ & $15 \%$ & $0 \%$ \\
\hline Tema escolhido pelo orientador & $39 \%$ & $27 \%$ & $45 \%$ & $27 \%$ & $0 \%$ \\
\hline
\end{tabular}

$\mathrm{Na}$ Tabela 2 foram organizados todos os fatores facilitadores em ordem decrescente de respostas, analisados mais profundamente os resultados obtidos por curso. Pode-se observar que os cursos que mais se destacam dentre os 4 primeiros fatores facilitadores mencionados na pesquisa são os Cursos de Administração, Pedagogia e Ciências Biológicas. O Curso de Enfermagem não teve representatividade significativa nessas estatísticas, tendo em vista que nenhum dos respondentes optou pelos fatores facilitadores elencados. Conclui-se, avaliando a Tabela 2, que os entrevistados assinalam que, de forma geral o corpo docente, o Projeto Pedagógico do Curso e a infraestrutura da universidade têm contribuído positivamente para dotá-los das condições necessárias para o sucesso na elaboração do TCC. Em relação à questão 6 [Durante a elaboração do seu TCC, houve algum fator facilitador que não foi mencionado na questão 5? Qual?], assim responderam os participantes:

Tabela 3: Fatores Facilitadores apontados pelos entrevistados.

\begin{tabular}{l|l}
\hline Fatores Facilitadores & $\%$ \\
\hline Ajuda e troca de conhecimentos com amigos & $11 \%$ \\
\hline Residência Universitária, gerando praticidade quanto ao acesso aos recursos didáticos & $11 \%$ \\
\hline Receptividade dos participantes com a pesquisa & $34 \%$ \\
\hline Campo de pesquisa & $11 \%$ \\
\hline Acesso ao professor antes de iniciar a pesquisa & $11 \%$ \\
\hline Proposta de pesquisas futuras de outros estudos & $11 \%$ \\
\hline Acesso à Internet & $11 \%$ \\
\hline
\end{tabular}

$\mathrm{Na}$ Tabela 3 foram apontados espontaneamente pelos entrevistados alguns aspectos facilitadores que não foram mencionados na pesquisa. A maioria respondeu que a receptividade dos participantes com a pesquisa é muito importante, uma vez que para o sucesso de um trabalho monográfico é preciso que os entrevistados queiram responder (questionário ou entrevista). Assim, responderam com maior fidelidade às 
perguntas feitas foram relatados ainda que a ajuda e a troca de conhecimentos com amigos facilitaram nesse processo, o qual, na maioria das vezes, muitos discentes se ajudam e vão construindo juntos, ajudando um ao outro. Outro fator mencionado foi residir na Residência Universitária, considerando que muitos dos discentes são de outras cidades e não têm como ficar viajando todos os dias para a sua cidade. Ao dispor da Residência Universitária como apoio, faz com que tenham um maior tempo para estudar e ainda uma maior facilidade quanto ao acesso aos recursos didáticos, ao professor e à própria estrutura da instituição.

Ainda de acordo com a Tabela 3, foi mencionado que o acesso ao professor antes de iniciar a pesquisa é primordial para o caminhar do processo, pois é aí que o discente percebe se realmente o orientador tem disponibilidade e domínio do tema que ele desenvolver. Outro fator mencionado foram as propostas para pesquisas futuras. Muitos discentes, ao se depararem com a etapa de escolha do tema, acabam lendo outros trabalhos feitos que tenham afinidade e terminam escolhendo temas propostos nesses trabalhos, sendo de muita importância para aqueles que não têm um tema ainda definido. Isto é possível na medida em que os discentes se envolvem de fato com a pesquisa e buscam, no acervo bibliográfico, o apoio necessário para promover o comprometimento da pesquisa.

Também foi apontado o acesso à Internet como fator relevante no processo de elaboração do TCC. Trata-se, sem dúvida, de uma ferramenta fundamental para a construção do trabalho, pois pela Internet se pode pesquisar sobre o tema nos mais variados repositórios e arquivos de dissertações e teses. Ademais, vale salientar que os alunos da UFPI do Campus Floriano têm livre acesso à rede mundial de computadores, visto que o wifi é aberto a todos. Também foi perguntado aos egressos os fatores que, na opinião deles, constituem dificuldades ou embaraços no processo de operacionalização do TCC. O Gráfico 3 e a Tabela 4 indicam estas características, as quais precisam de melhor apuração, pois o rol de alternativas foi significativo, sugerindo que os docentes e discentes repensem meios que possam conciliar os mais variados interesses e demandas, tendo em vista que a construção de um trabalho monográfico exige, de ambas as partes, um grau de compromisso elevado.

\section{Fatores Dificultadores}

O Gráfico 3 mostra os fatores dificultadores relatados entre os 4 cursos pesquisados. Os que mais prevaleceram foram a mudança de orientador, o tema escolhido pelo orientador, o tempo a ser destinado ao TCC e o custo envolvido. A mudança de orientador, que por muitas das vezes se dá pelo término de contrato do professor (substituto), processo de remoção ou então quando o orientador não tem domínio do conteúdo, tendo que passar o orientando para outro professor, independentemente do motivo pelo qual o orientando teve que mudar do orientador, é muito difícil para o discente esta ruptura, porque em muitos casos o novo orientador vem com outra visão e acaba tendo que mudar quase todo o trabalho, gerando perdas consideráveis para o discente. Um outro fator mencionado foi o tema escolhido pelo orientador. No momento em que o orientando solicita um tema para o orientador ou sugere algum tema, o professor tenderá a escolher um assunto que ele tenha domínio, situação esta que, em muitas oportunidades, acaba sendo uma dificuldade para o discente, porque o orientando não tem nenhuma afinidade com o tema 
escolhido e acaba fazendo só porque foi o orientador que escolheu. Outro fator dificultador, segundo os entrevistados, foi o acervo da biblioteca. De acordo com os participantes, a falta de títulos na biblioteca faz com que o trabalho acabe tendo um grau de dificuldade maior, já que a biblioteca, nem sempre, dispõe dos títulos que o trabalho/tema exige.

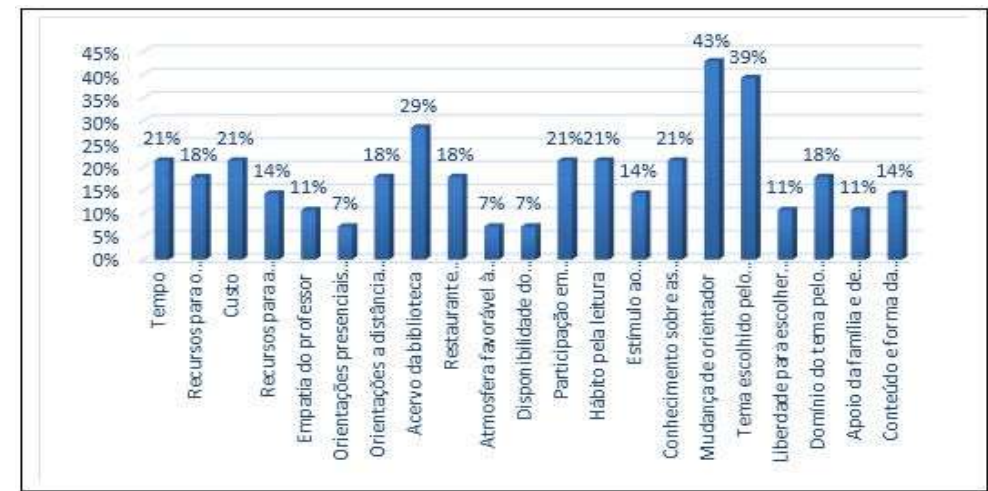

Gráfico 3: Fatores Dificultadores para a construção do TCC.

Também foi apontado como fator dificultador o tempo, estando tal posição diretamente relacionada a cada curso, pois em alguns Cursos de Graduação o Trabalho de Conclusão de Curso se divide em 2 ou 3 etapas, implicando num empenho maior por parte do formando. Porém, por mais que o TCC seja dividido em etapas, existem outras dificuldades que acabam fazendo com que o tempo seja um fator obstaculizador, pode ser que o discente esteja cursando concomitantemente outras disciplinas, estágio obrigatório, etc., e isto acaba consumindo todo o seu tempo, dedicando-se menos à pesquisa.

Por último, um fator mencionado foi o custo. Alguns trabalhos acabam requerendo um desembolso maior para investir na pesquisa do que em outros. Por mais que alguns discentes trabalhem, muitos ainda são dependentes dos pais e não têm como arrecadar fundos para o desenvolvimento da pesquisa. 0 elemento custo envolve acesso à Internet para pesquisar artigos, dissertações e teses; impressão de material; encadernamento; deslocamentos extras para a universidade fora das rotas dos ônibus, pagamento de refeições ou lanches; aquisição de material de expediente, etc.. O cenário mencionado encontra convergência nos estudos desenvolvidos por Carboni et al. (2004) e Santos et al. (2017), para quem vários foram os fatores impeditivos para a elaboração do TCC: tempo, custos, procura de um orientador, construção textual, delimitação do tema para pesquisa, identificação de referências para serem utilizadas no trabalho, aplicação das normas ABNT e realização das etapas científicas que são exigidas ao trabalho científico. Conforme o Gráfico 3, pode-se afirmar que mais uma vez o orientador é fundamental para a construção do TCC, pois, caso o orientando não tenha êxito na escolha do mesmo, acabará tendo dificuldades, seguido da falta de tempo para executá-lo e do custo para mantê-lo.

Tabela 4: Fatores Dificultadores para a construção do TCC por curso.

\begin{tabular}{l|l|l|l|l|l}
\hline Fatores Dificultadores & \multicolumn{1}{l|}{ Cursos } \\
\hline Aspecto & $\%$ & Administração & Pedagogia & Ciências Biológicas & Enfermagem \\
\hline & & & & & \\
Mudança de orientador & $43 \%$ & $33 \%$ & $33 \%$ & $25 \%$ & $8 \%$ \\
\hline Tema escolhido pelo orientador & $39 \%$ & $45 \%$ & $27 \%$ & $18 \%$ & $9 \%$ \\
\hline Acervo da biblioteca & $29 \%$ & $38 \%$ & $50 \%$ & $13 \%$ & $0 \%$ \\
\hline
\end{tabular}




\begin{tabular}{l|l|l|l|l|l}
\hline Tempo & $21 \%$ & $83 \%$ & $0 \%$ & $0 \%$ & $17 \%$ \\
\hline Custo direto e indireto para a elaboração do TCC & $21 \%$ & $50 \%$ & $33 \%$ & $17 \%$ & $0 \%$ \\
\hline Participação em projetos de Iniciação Científica (IC) & $21 \%$ & $83 \%$ & $0 \%$ & $0 \%$ & $17 \%$ \\
\hline Hábito pela leitura & $21 \%$ & $67 \%$ & $33 \%$ & $0 \%$ & $0 \%$ \\
\hline Conhecimento sobre as Normas da ABNT & $21 \%$ & $50 \%$ & $50 \%$ & $0 \%$ & $0 \%$ \\
\hline Recursos para o deslocamento até o campus & $18 \%$ & $40 \%$ & $40 \%$ & $20 \%$ & $0 \%$ \\
\hline Orientações a distância sistemáticas & $18 \%$ & $40 \%$ & $40 \%$ & $0 \%$ & $20 \%$ \\
\hline Restaurante Universitário funcionando no jantar & $18 \%$ & $60 \%$ & $20 \%$ & $20 \%$ & $0 \%$ \\
\hline Domínio do tema pelo orientador & $18 \%$ & $40 \%$ & $40 \%$ & $0 \%$ & $20 \%$ \\
\hline Recursos para a realização da pesquisa de campo & $14 \%$ & $25 \%$ & $50 \%$ & $0 \%$ & $25 \%$ \\
\hline Estímulo ao desenvolvimento da pesquisa & $14 \%$ & $50 \%$ & $25 \%$ & $0 \%$ & $25 \%$ \\
\hline Empatia do professor & $11 \%$ & $33 \%$ & $33 \%$ & $0 \%$ & $33 \%$ \\
\hline Liberdade para escolher o tema & $11 \%$ & $33 \%$ & $33 \%$ & $0 \%$ & $33 \%$ \\
\hline Apoio da família e de amigos & $11 \%$ & $67 \%$ & $33 \%$ & $0 \%$ & $0 \%$ \\
\hline Orientações presenciais sistemáticas & $7 \%$ & $0 \%$ & $50 \%$ & $0 \%$ & \\
\hline Atmosfera favorável à docência & $7 \%$ & $50 \%$ & $0 \%$ & $0 \%$ & $50 \%$ \\
\hline Disponibilidade do orientador & $7 \%$ & $0 \%$ & $50 \%$ & $0 \%$ & $50 \%$ \\
\hline
\end{tabular}

Na Tabela 4 foram organizados todos os fatores dificultadores em ordem decrescente de relevância, analisando as respostas obtidas pelos participantes de cada curso. Observa-se que na maioria das respostas os cursos que tiveram percentuais elevados quanto aos fatores dificultadores foram os Cursos de Administração, Pedagogia e Ciências Biológicas. Em relação à Questão 7 [Durante a elaboração do seu TCC, houve algum fator dificultador que não foi mencionado na questão 5? Qual?] Foram obtidas respostas, conforme se constata na Tabela 5.

Tabela 5: Fatores Dificultadores apontados pelos entrevistados.

\begin{tabular}{l|l}
\hline Fatores Dificultadores & $\%$ \\
\hline Escolha do tema & $8 \%$ \\
\hline Fatores psicológicos & $8 \%$ \\
\hline Recursos didáticos indisponíveis & $17 \%$ \\
\hline Elaboração do texto da pesquisa & $8 \%$ \\
\hline Fatores climáticos & $8 \%$ \\
\hline Campo de pesquisa & $8 \%$ \\
\hline Falhas na orientação & $8 \%$ \\
\hline Dificuldades na análise dos dados & $8 \%$ \\
\hline Vínculo trabalhista impedindo a conciliação de tempo & $17 \%$ \\
\hline Troca de orientador & $8 \%$ \\
\hline
\end{tabular}

Na Tabela 5 foram relatadas as dificuldades apontadas pelos entrevistados, as quais não foram mencionadas quando do envio do questionário. Esta questão foi aberta e livre, permitindo que os participantes expusessem algum fator dificultador adicional, além daqueles que compuseram a pesquisa na origem. Foi relatado, com um percentual de 17\%, a falta de recursos didáticos. Algumas pesquisas, por serem pioneiras no campo, mesmo em se tratando de um produto monográfico, acabam promovendo alguma dificuldade aos alunos para encontrar material para a sua elaboração. Outro fator mencionado foi o vínculo empregatício, ou seja, a dificuldade em conduzir a conciliação entre emprego e estudo. Na maioria dos casos, o fato de ter um emprego acaba sendo um fator dificultador. Foi relatado também a escolha do tema, restando notório que muitos não sabem que área escolher e nem sobre o que quer discorrer cientificamente, gerando, portanto, um elemento de dificuldade.

Foi apontado como dificultador fatores psicológicos (ansiedade), como a tensão de ter o seu primeiro contato com um TCC, gerando ao discente uma teia de ansiedade na construção do trabalho, levando-o a 
outra dificuldade, a qual é muito comum em muitos que estão no seu primeiro trabalho, que é a elaboração do texto da pesquisa. A imersão na pesquisa, a qual exige do participante um leque de aptidões e, acima de tudo, uma percepção crítica e interpretativa dos conceitos que precisarão embasar os estudos, implica em outro elemento de complexificação do TCC. As dificuldades relacionadas à análise criteriosa e analítica de conceitos e dados têm gerado repercussões conflitantes entre orientando e orientadores, talvez porque a base cognitiva do formando necessite de adequações face às lacunas que advêm da Educação Básica.

É importante lembrar que o Campus Amílcar Ferreira Sobral foi criado em 2009, a partir do REUNI Programa de Apoio a Planos de Reestruturação e Expansão das Universidades Federais, cujas ações contemplaram "[...] o aumento de vagas nos cursos de graduação, a ampliação da oferta de cursos noturnos, a promoção de inovações pedagógicas e o combate à evasão, entre outras metas que têm o propósito de diminuir as desigualdades sociais no país" (BRASIL, 2010). Outro fator mencionado, conforme a Tabela 5, foi a dificuldade na análise dos dados. Observou-se que é muito comum que os discentes tenham essa dificuldade na hora de analisar os dados, já que para muitos é a sua primeira experiência com os métodos quantitativos/qualitativos. Foi citado também que a falha na orientação é um fator dificultador, e isto se dá quando não há o entendimento no que o orientador está pedindo e o que o orientando está precisando produzir, ocasionando assim esta lacuna. Assim como campo de pesquisa foi um facilitador, ele também pode ser um dificultador, caso não haja uma definição clara e concisa do campo de pesquisa, visto que, ao invés de facilitar a sua pesquisa, o campo escolhido produzirá efeitos contrários. Por fim, foi questionado a situação final do discente, após a apresentação do seu TCC, através da pergunta 8 [Qual a situação final após a apresentação do seu TCC?]. Os posicionamentos estão agrupados no Gráfico 4.

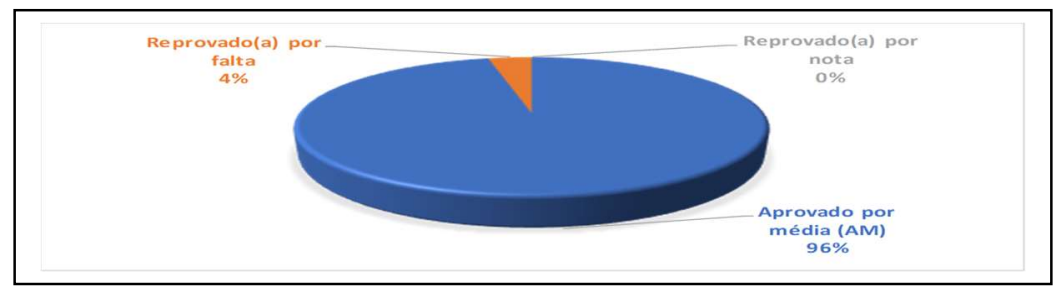

Gráfico 4: Situação após a apresentação do seu TCC.

O Gráfico 4 mostra que dentre os respondentes praticamente todos foram aprovados nos seus trabalhos, mostrando mesmo que havendo fatores facilitadores e dificultadores, o que mais prevaleceu foram os facilitadores, tendo em vista que $96 \%$ obtiveram êxito na elaboração do TCC, enquanto que $4 \%$ foram reprovados, por falta.

Tendo em vista o objetivo do estudo, o problema da pesquisa e os dados coletados em campo, foi possível resumir quais os fatores estão relacionados no processo de elaboração do Trabalho de Conclusão de Curso nos Cursos de Graduação do Campus Amílcar Ferreira Sobral, conforme agrupamento trazido no Quadro 5. Optou-se por classificar os fatores em 4 grupos: Social, Psicológica, Produção Técnica e Econômica, cada uma correspondendo a uma categoria de análise e concepção, facilitando a aferição dos fatores que envolvem a elaboração do TCC. Algum dos fatores podem se enquadrar em mais de uma categoria. 
Quadro 5: Classificação das categorias pesquisadas.

\begin{tabular}{|c|c|c|c|}
\hline Categorias & \multicolumn{3}{|l|}{ Fatores } \\
\hline Social & \multicolumn{3}{|c|}{$\begin{array}{l}\text { Restaurante Universitário funcionando no jantar } \\
\text { Permanência na Residência Universitária } \\
\text { Receptividade dos participantes com a pesquisa }\end{array}$} \\
\hline Psicológica & \multicolumn{3}{|c|}{$\begin{array}{l}\text { Empatia do professor } \\
\text { Apoio da família e de amigos } \\
\text { Estímulo ao desenvolvimento da pesquisa } \\
\text { Ansiedade } \\
\text { Tensão }\end{array}$} \\
\hline Produção Técnica & $\begin{array}{ll}- & \text { Disponibilidade do orientador } \\
\text { - } & \text { Liberdade para escolher o tema } \\
\text { - } & \text { Domínio do tema pelo orientador } \\
\text { - } & \text { Orientações presenciais sistemáticas } \\
\text { - } & \text { Conteúdo e forma da pesquisa } \\
\text { - } & \text { Orientações a distância sistemáticas } \\
\end{array}$ & $\begin{array}{ll}- & \mathrm{A} \\
\text { - } & \mathrm{T} \\
\text { - } & \mathrm{A} \\
\text { - } & \mathrm{H} \\
\text { - } & \mathrm{P} \\
\text { - } & \mathrm{N} \\
\text { - } & \mathrm{T} \\
\text { - } & \mathrm{P} \\
\text { - } & \mathrm{A}\end{array}$ & $\begin{array}{l}\text { Atmosfera favorável à docência } \\
\text { Tempo } \\
\text { Acervo da biblioteca } \\
\text { Hábito pela leitura } \\
\text { Participação em projetos de Iniciação Científica } \\
\text { Mudança de orientador } \\
\text { Tema escolhido pelo orientador } \\
\text { Propostas de pesquisas futuras } \\
\text { Análise dos dados }\end{array}$ \\
\hline Econômica & $\begin{array}{ll}\text { - } & \text { Recursos para a realização da pesquisa } \\
\text { - } & \text { Custos envolvidos com a produção da } \\
\text { - } & \text { Recursos para o deslocamento até o } c \\
\text { - } & \text { Possibilidade de acesso à Internet } \\
\end{array}$ & $\begin{array}{l}\text { e campo } \\
\text { onografia } \\
\text { pus }\end{array}$ & \\
\hline
\end{tabular}

A partir da análise do conjunto dos fatores que compõem o processo de formatação do TCC, foi possível desenvolver o Quadro 5 emergindo quatro categorias, as quais reúnem discriminadamente os fatores positivos e negativos relacionados à construção do TCC.

\section{CONCLUSÕES}

O objetivo deste estudo foi investigar os elementos determinantes da elaboração do Trabalho de Conclusão de Curso da Graduação, a partir de aplicação de questionário junto aos egressos dos Cursos de Bacharelado em Administração e Enfermagem e de Licenciatura em Ciências Biológicas e em Pedagogia da Universidade Federal do Piauí (UFPI) - Campus Amílcar Ferreira Sobral, Floriano/PI. O estudo apresentou, de forma classificada e posteriormente agrupando por categorias, os fatores que prevaleceram nos achados de campo relacionados às dificuldades e facilidades pertinentes à construção do TCC.

Respondendo aos objetivos da pesquisa, constatou-se que os fatores facilitadores mais relevantes para a elaboração do TCC são a empatia do professor, a disponibilidade do orientador, a liberdade para escolher o tema, o domínio do tema pelo orientador e o apoio da família e amigos. Por outro lado, destacamse como fatores dificultadores a mudança de orientador, o tema escolhido pelo orientador, o acervo da biblioteca, o tempo e o custo direto e indireto para a elaboração do TCC, sendo, para os pesquisados, pontos que impactam diretamente no processo de elaboração do produto monográfico.

Categorizados, pode-se concluir que os aspectos facilitadores que prevaleceram foram os de Categorias de Produção Técnica e Psicológica. Já os principais aspectos dificultadores podem ser classificados como de Categorias de Produção Técnica e Econômica. Vê-se, neste contexto, que os fatores inseridos na Categoria de Produção Técnica se sobressaem, estando presentes tanto nos aspectos facilitadores, quanto nos dificultadores. Este estudo teve como propósito contribuir com os Cursos de Administração, Ciências Biológicas, Enfermagem e Pedagogia não apenas do Campus Amílcar Ferreira Sobral/UFPI, os quais, diante 
dos resultados apresentados, poderão adotar medidas didático-pedagógicas junto ao corpo docente visando à redução da ansiedade, nervosismo, insegurança e outros possíveis fatores relacionados à construção do TCC, assim como adotar medidas que proporcionem uma infraestrutura adequada (Restaurante Universitário, Residência Universitária, acervo bibliográfico, Internet veloz, etc.) para permitir que as pesquisas desenvolvidas na etapa do TCC, considerada obrigatória para a obtenção do título de graduado, alcancem exitosamente os objetivos.

Para os sujeitos investigados, o estudo possibilitará uma autocrítica diante do resultado, permitindo rever os aspectos relacionados ao processo de elaboração do TCC, buscando se apoiar em conduta estimuladora e incentivadora do corpo docente e do professor-orientador, com a finalidade de atenuar os elementos psicológicos, materiais e emocionais que orbitam a construção do produto científico (TCC), necessário à sua formação, enquanto profissional do campo.

O prosseguimento desse estudo é de extrema importância para a compreensão real e efetiva das implicações que há no processo de construção do TCC, uma vez que este componente curricular, não raro, é considerado um dos grandes entraves para a conclusão do Curso de Graduação (Bacharelado ou Licenciatura), promovendo clara apreensão aos formandos. Adicionalmente, o estudo contribuirá para a produção científica sobre o tema, permitindo novas perspectivas de estudo, novas metodologias, além do aprofundamento teórico. Como proposta para estudos futuros, sugere-se a replicação do estudo com o fito de alcançar um número maior de respondentes nos cursos pesquisados; a ampliação dos estudos para outras áreas com o intuito de aumentar o número de cursos sob investigação e o ingresso de outras IES - Instituições de Ensino Superior na análise, para fins de comparação e análise visando, sempre, a busca dos melhores métodos de orientação e condução do produto monográfico.

\section{REFERÊNCIAS}

APPOLINÁRIO, F.. Metodologia da Ciência: filosofia e prática da pesquisa. 2 ed. São Paulo: Cengage Learning, 2016.

BRASIL. Conselho Nacional de Educação. Resolução CES/CNE n. 04 de 13 de julho de 2005: Diretrizes Curriculares Nacionais para os Cursos de Graduação em Administração. Brasília: MEC, 2005.

BRASIL. Conselho Nacional de Educação. Resolução CNE/CES n. 04, de 15 de maio de 2006. Brasília: DOU, 2006.

BRASIL. Conselho Nacional de Educação. Resolução n. 7, de 11 de março de 2002: Diretrizes curriculares nacionais para os Cursos de Ciências Biológicas. Brasília: MEC, 2002.

BRASIL. Conselho Nacional de Educação. Resolução CNE/CES n. 3, de 7 de novembro de 2001: Resolução Diretrizes Curriculares Nacionais do curso de graduação em enfermagem. Brasília: MEC, 2001.

BRASIL. Conselho Nacional de Educação. Lei n. 9.394, de 20 de dezembro de 1996. Diretrizes e Bases da Educação Nacional (LDB). Brasília: MEC, 1996.
CAMPOS, A. M.; CORRÊA, M. H.. Possíveis causas da não conclusão da monografia pelos ex-alunos do Curso de Mestrado da Ebap. Revista de Administração Pública, v.16, n.3, p.89-114, 1982

CARBONI, R. M.; NOGUEIRA, V. O.. Facilidades e dificuldades na elaboração de trabalhos de conclusão de curso. ConScientiae Saúde, São Paulo, v.3, p.65-72, 2004

CERVO, A. L.; BERVIAN, P. A.; SILVA, R.. Metodologia científica. 6 ed. São Paulo: Pearson Prentice Hall, 2007.

CUNHA, L. C.; VOGT, M.; BIAVATTI, V. T.. Contribuições do Trabalho de Conclusão de Curso e do Estágio Curricular para a Aprendizagem: Percepção dos Alunos dos Cursos de Ciências Contábeis. Contabilidade Vista \& Revista, v.26, n.1, p.57-78, 2015.

DURANTE, D. G.; RIBEIRO, J. L. S.; ROCHA, T. L. C. G..

Produção monográfica: significados e dificuldades na visão dos estudantes. R. G. Secr. GESEC, São Paulo, v.10, n.1, p.2646, 2019.

ENGLERT, N. F; FRIO, R. S.; SALDANHA, C. S. V.; ROSSI, C. A. V.. Redução do escopo ou ampliação da prática? As 
perspectivas do marketing na visão de seus acadêmicos. Revista Eletrônica de Administração, v.24, n.2, p.167-188, 2018.

MÜLLER, M. S.; CORNELSEN J. M.. Normas e padrões para teses, dissertações e monografias. 5 ed. Londrina: Eduel, 2003.

NEVES, J. M. S.; RUSSI, L. N.. O TCC como Ferramenta para Consolidação das Competências Adquiridas no Ensino de Tecnologia na Fatec Guaratinguetá (SP). In: ENCONTRO DE ENSINO E PESQUISA EM ADMINISTRAÇÃO E

CONTABILIDADE, 1. Anais. Recife: ANPAD, 2007.

PEIXOTO, E. P. A.; FRANÇA, R. D.; ANDRADE, E. P. A.; MENÊSES, F. A. F. A.. A contribuição da iniciação científica na elaboração do TCC no curso de Ciências Contábeis sob a ótica do corpo discente: uma pesquisa na IES públicas do Estado da Paraíba. In: CONGRESSO USP DE INICIAÇÃO CIENTÍFICA EM CONTABILIDADE, 11. Anais. São Paulo: USP, 2014.
SANTOS, C. K. S.; LEAL, E. A.; NUNES, I. V.; SILVA, T. D..

Pesquisa Científica no Curso de Ciências Contábeis: Limites e Contribuições ao Aluno na Elaboração do Trabalho de Conclusão de Curso. Revista Evidenciação Contábil \& Finanças, v.5, n.3, p.140-156, 2017.

SEVERINO, A. J.. Metodologia do trabalho científico. 23 ed. São Paulo: Cortez, 2007.

SILVA, A. G.; MORAIS, F. M. S. G.; FARIAS, I. P.; MEDEIROS, P. M.; ARAÚJO, J. G. N.. Dificuldades do Docente no Processo de Orientação em Trabalhos de Conclusão de Curso: Um Estudo em Cursos de Ciências Contábeis em Instituições de Ensino Superior da Grande Recife. Revista Evidenciação Contábil \& Finanças, v.7, n.1, p.20-37, 2019.

SKORA, C. M.; MENDES, D.; SOUZA, H. E. L.; CARVALHO, O. C.. Os Critérios do Prêmio Nacional da Qualidade e a Formação do Administrador: uma alternativa para Trabalho de Conclusão de Curso (TCC). In: ENANPAD, 30. Anais. Rio de Janeiro: ANPAD, 2006. 